\title{
Abscisic Acid Standardized Fig (Ficus carica) Extracts Ameliorate Postprandial Glycemic and Insulinemic Responses in Healthy Adults
}

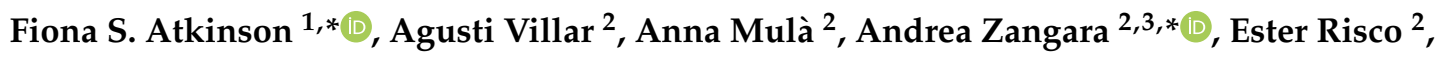 \\ Carsten R. Smidt ${ }^{4}$, Raquel Hontecillas ${ }^{5}$, Andrew Leber ${ }^{5}$ and Josep Bassaganya-Riera ${ }^{5}$ \\ 1 School of Life and Environmental Sciences and Charles Perkins Centre, D17, The University of Sydney, \\ Sydney, NSW 2006, Australia \\ 2 Euromed S.A., C/ Rec de Dalt, 21-23, Pol. Ind. Can Magarola, 08100 Mollet del Valles, Barcelona, Spain \\ 3 Centre for Human Psychopharmacology, Swinburne University, Melbourne, VIC 3122, Australia \\ 4 Smidt Labs, LLC, Sandy, UT 84092, USA \\ 5 BioTherapeutics, Inc, 1800 Kraft Drive, Suite 200, Blacksburg, VA 24060, USA \\ * Correspondence: fiona.atkinson@sydney.edu.au (F.S.A.); azangara@euromed.es (A.Z.)
}

Received: 30 June 2019; Accepted: 29 July 2019; Published: 31 July 2019

check for updates

\begin{abstract}
Abscisic acid (ABA) can improve glucose homeostasis and reduce inflammation in mammals by activating lanthionine synthetase C-like 2 (LANCL2). This study examined the effects of two fig fruit extracts (FFEs), each administered at two different ABA doses, on glycemic index (GI) and insulinemic index (II) to a standard glucose drink. In a randomized, double-blind crossover study, 10 healthy adults consumed 4 test beverages containing FFE with postprandial glucose and insulin assessed at regular intervals over $2 \mathrm{~h}$ to determine GI and II responses. Test beverages containing $200 \mathrm{mg}$ FFE-50x and $1200 \mathrm{mg}$ FFE-10× significantly reduced GI values by $-25 \%(P=0.001)$ and $-24 \%(P=0.002)$, respectively. Two lower doses of FFE also reduced GI values compared with the reference drink (by approximately $-14 \%$ ), but the differences did not reach statistical significance. Addition of FFE to the glucose solution significantly reduced II values at all dosages and displayed a clear dose-response reduction: FFE-50× at $100 \mathrm{mg}$ and $200 \mathrm{mg}(-14 \%(P<0.05)$ and $-24 \%(P=0.01)$, respectively) and FFE-10× at $600 \mathrm{mg}$ and $1200 \mathrm{mg}(-16 \%(P<0.05)$ and $-24 \%(P=0.01)$, respectively). FFE supplementation is a promising nutritional intervention for the management of acute postprandial glucose and insulin homeostasis, and it is a possible adjunctive treatment for glycemic management of chronic metabolic disorders such as prediabetes and type 2 diabetes mellitus.
\end{abstract}

Keywords: abscisic acid; fig fruit extract; glycemic index; insulinemic index

\section{Introduction}

Impaired glucose tolerance (IGT), or prediabetes, an intermediate state with plasma glucose levels ranging between normoglycemia and diabetes, is an important health concern [1,2]. In 2017, approximately 352 million people worldwide were living with IGT, and its prevalence is projected to increase to 587 million by 2045 [2]. The Centers for Disease Control and Prevention estimated that 84 million adults in the US had prediabetes in 2015, which represented approximately $34 \%$ of the adult population at the time [3]. Metabolic syndrome, an independent risk factor for both microvascular and macrovascular diseases, is closely related to IGT and insulin resistance. In 2017, approximately USD 44 billion was spent on healthcare due to prediabetes in the US [2]. Moreover, people with IGT and prediabetes are at a high risk of progressing to type 2 diabetes mellitus [1], potentially creating an even larger burden on the health system. 
Prediabetes management involves dietary and lifestyle modifications, along with weight loss in obese individuals, with a primary goal of restoring normoglycemia and maintaining $\beta$-cell function $[4,5]$. Plant-based supplements are generally safer with fewer side effects compared with synthetic drugs [6,7] and, therefore, may offer promising options for the prevention and treatment of chronic diseases, such as type 2 diabetes mellitus. Abscisic acid (ABA), a phytohormone commonly present in fruits and vegetables, has been shown in mammals to not only promote peripheral glucose uptake [8,9] but also to possess adaptogenic properties related to the stress response [10]. Long-term oral administration of exogenous $\mathrm{ABA}$ reduced fasting plasma glucose concentrations and ameliorated glucose tolerance in leptin receptor-deficient $(\mathrm{db} / \mathrm{db})$ mice [9]. Mechanistically, the ABA receptor has been proposed to be lanthionine synthetase C-like 2 (LANCL2) [11]. The signaling pathway downstream of LANCL2 includes a G-protein-mediated activation of adenylate cyclase, cAMP production, and activation of protein kinase A [12]. In addition, LANCL2 can facilitate phosphorylation of Akt by mTORC2 via direct physical interactions [13]. Active mTORC2 causes translocation of GLUT4 to the plasma membrane and stimulates glucose uptake [14].

In healthy adults, plasma concentration of ABA increases following oral glucose administration, stimulating peripheral glucose uptake [15]. Individuals with diabetes have been shown to have suboptimal levels of endogenous ABA [16,17]. Moreover, at nanomolar concentrations, ABA stimulates glucose uptake in a manner similar to insulin [15]. Taken together, these studies suggest that ABA may play an important role in modulating glucose homeostasis in humans [18]. In fact, intake of an aqueous fruit extract containing $\mathrm{ABA}$ at $<1 \mu \mathrm{g} / \mathrm{kg}$ of body weight lowered glycemia and insulinemia during a standard meal in healthy volunteers [19]. ABA has received self-affirmed generally recognized as safe (GRAS, US FDA) status, and it has been evaluated as a safe substance by the US Environmental Protection Agency (EPA), posing no dietary risks to humans. Figs (Ficus carica L., Moraceae) are an important source of ABA (2812 pmol/g wet weight) [19]. Fig fruit extracts (FFEs) may potentially provide a natural method for controlling blood glucose and insulin fluctuations in metabolic and nutritional disorders, such as hyperglycemia and insulin resistance.

Glycemic index (GI) and insulinemic index (II) are common parameters used to assess the glycemic impact of foods, beverages, and dietary supplements. GI is a measure of carbohydrate quality and ranks products according to the extent to which the available carbohydrates in foods and beverages raise blood glucose compared to an equal carbohydrate portion of glucose [20]. The aim of this study was to determine the effects of two FFEs, standardized in ABA content and administered at two different dose levels, on postprandial glycemic and insulinemic responses relative to a standard glucose drink in healthy adults.

\section{Materials and Methods}

\subsection{Study Design and Participants}

This was a single-center, randomized, double-blind crossover study. The study was conducted using internationally recognized methods validated in multicenter research trials [21,22]. All experimental procedures were performed in accordance with international standards for conducting ethical research with humans and were approved by the Human Research Ethics Committee of the University of Sydney (Protocol: 2013/766). All participants provided written, informed consent before participation.

Ten healthy adults aged between $18-45$ years, with a body mass index (BMI) between $18-25 \mathrm{~kg} / \mathrm{m}^{2}$ and normal glucose tolerance, were recruited from a participant database from the Sydney University Glycemic Index Research Service. Normal glucose tolerance was assessed using the results from an oral glucose tolerance test conducted within the previous 1 month prior to participation in this study (fasting glucose $<5.5 \mathrm{mmol} / \mathrm{L}$ and $2 \mathrm{~h}$ postprandial glucose $<7.8 \mathrm{mmol} / \mathrm{L}$ ). Participants were excluded if they were over- or underweight, were dieting, had IGT, any illness, or food allergies, or were regularly taking any prescription medication other than standard contraceptives. 
Participants completed 7 test sessions each on a different day, with consecutive sessions separated by at least 1 day. Each participant tested the reference food (oral glucose solution containing $50 \mathrm{~g}$ of available carbohydrate) on sessions 1, 4, and 7 and one of the four test beverages during each of the remaining sessions in a random, counterbalanced order. Participants consumed the reference glucose drink on three separate occasions and each test beverage on one occasion only. Participants maintained their usual dietary and lifestyle patterns throughout the study.

\subsection{Study Treatments}

Pharmaceutical-grade dried FFEs (ABALife ${ }^{\mathrm{TM}}$, Euromed, Spain) were produced from Ficus carica L. fruit using a sophisticated, patent-pending process (EP17382616.5) and were standardized in ABA content. ABA content in these extracts was determined using reversed-phase ultra-high-performance liquid chromatography (UHPLC). Fig extracts contained one of two ABA concentrations: FFE-10X (ABA $\geq 300$ ppm by UHPLC, drug extract ratio (DER) of native extract is 50-60:1) and FFE-50× (ABA $\geq 50 \mathrm{ppm}$ by UHPLC, DER of native extract is 7-1:1). Two different concentrations of ABA $(10 \times$ or $50 \times)$ were used in this study to ensure that any effects on glycemic and insulinemic responses were due to ABA content and not to other compounds in the fig matrix. Each extract (FFE-10 $\times$ or FFE-50 $\times$ ) was tested at two doses equivalent to $40 \mu \mathrm{g}$ (lower dose) and $80 \mu \mathrm{g}$ (higher dose) ABA.

The reference beverage and the four test beverages all contained $50 \mathrm{~g}$ of available carbohydrate in the form of an oral glucose solution prepared as $51.4 \mathrm{~g}$ Glucodin ${ }^{\mathrm{TM}}$ powder (Valeant Pharmaceuticals, Australia) dissolved in $250 \mathrm{~mL}$ water. The oral glucose solutions for the reference and test beverages were prepared the day before required and stored in the refrigerator overnight. The FFE required for each test beverage was added into the glucose solution immediately prior to being served to a participant. The four FFE treatments were $100 \mathrm{mg}$ FFE-50×, $200 \mathrm{mg}$ FFE-50×, $600 \mathrm{mg}$ FFE-10×, and 1200 mg FFE-10x. The nutritional contents of the reference glucose drink and test beverages were identical, except for addition of the FFE powder in the test beverages. Both participants and researchers were blinded to the differences between the extracts and the ABA doses of the test beverages throughout the study.

\subsection{Study Procedures}

The night before each test session, participants consumed a carbohydrate-based evening meal, excluding legumes and alcohol, and then arrived at the research center in the morning after fasting overnight for at least $10 \mathrm{~h}$. Two fasting capillary blood samples were collected from a warmed hand ( $\geq 0.5 \mathrm{~mL}$ blood into $1.5 \mathrm{~mL}$ tubes containing $10 \mathrm{IU}$ heparin) from each participant before administration of the reference or test beverage. The 2 fasting samples were collected $5 \mathrm{~min}$ apart, and the average concentration of these timepoints was used as the baseline concentration. The reference glucose drink or test beverage (containing 100 or 200 mg FFE-50x or 600 or 1200 mg FFE-10x; both extract doses equivalent to either 40 or $80 \mu \mathrm{g}$ ABA, respectively, mixed in the reference glucose drink) was administered along with $250 \mathrm{~mL}$ of plain water, which was consumed within $12 \mathrm{~min}$. Additional finger-prick blood samples were collected at 15, 30, 45, 60, 90, and 120 min after starting consumption of the reference or test beverage.

Capillary blood samples were centrifuged at $10,000 \times g$ for $45 \mathrm{~s}$ immediately after collection. Plasma samples were then immediately transferred into labeled, uncoated tubes and stored at $-30{ }^{\circ} \mathrm{C}$ for later analysis. Plasma glucose concentrations were evaluated in duplicate using a glucose hexokinase enzymatic assay (Beckman Coulter Inc., Brea, CA, USA.) on an automatic centrifugal spectrophotometric clinical chemistry analyzer (Beckman Coulter AU480 ${ }^{\circledR}$, Beckman Instruments Inc., Brea, CA, USA). Plasma insulin concentrations were measured using an insulin sandwich type enzyme-linked immunoassay (Insulin ELISA kit, ALPCO ${ }^{\circledR}$, Salem, NH, USA), respectively. All seven test sessions for each participant were analyzed within the same assay. 


\subsection{Data Analysis and Statistical Analysis}

The incremental area under the plasma glucose or insulin response curves over $2 \mathrm{~h}$ (iAUC), ignoring the area below fasting concentration, were calculated using the trapezoidal rule. Glycemic index (GI) and insulinemic index (II) values were then calculated for each participant's test beverages by expressing the iAUC response for a given test beverage as a percentage of the average response produced by the reference beverage in the same individual [20]. Sample-size calculations based on data from published GI studies suggested 10 participants were required in order to detect a significant difference among GI and II values with $90 \%$ power [20]. Comparative analyses were performed on glucose and insulin variables (GI, II, iAUC and peak postprandial responses) using analysis of variance (ANOVA) and the least significant difference (LSD) test for multiple comparisons. IBM $^{\circledR}$ SSPS $^{\circledR}$ Statistic software 24 was used for all statistical analyses. Linear regression analysis was used to assess the association between ABA dose and postprandial GI or II responses of the beverages. No outlier responses were excluded from the analyses. Results are expressed as means with standard error of mean (SEM). Statistical significance was set at $P<0.05$.

\section{Results}

\subsection{Participant Characteristics}

A total of 10 healthy adults ( 7 women and 3 men; 7 White/Caucasian, 1 Hispanic, and 2 Asian) with a mean ( \pm standard deviation) age of $29.5 \pm 10.1$ years and an average body mass index of $22.1 \pm$ $2.0 \mathrm{~kg} / \mathrm{m}^{2}$ completed the study. All participants completed the 7 test visits and associated protocols (dropout rate: $0 \%$ ). The mean within-individual coefficient of variation for the glycemic responses for the three repeated reference glucose solution treatments was $11 \%$, which was within the accepted level of $\leq 30 \%$ [22].

\subsection{Tolerability of Test Beverages}

The FFE when consumed at both the lower doses (100 mg FFE-50x and $600 \mathrm{mg}$ FFE-10x; equivalent to $40 \mu \mathrm{g} \mathrm{ABA}$ ) and higher doses (200 mg FFE-50× and $1200 \mathrm{mg}$ FFE-10x; equal to $80 \mu \mathrm{g}$ of ABA) were palatable and well tolerated. No adverse events were reported.

\subsection{Two-Hour Plasma Glucose and Insulin Responses for Reference Beverage and Test Beverages}

Following ingestion of the reference beverage or test beverage, average plasma glucose concentrations reached a peak at $30 \mathrm{~min}$ and gradually declined to preprandial levels by $120 \mathrm{~min}$ (Figure 1). Higher doses of the two FFEs (200 mg FFE-50× and $1200 \mathrm{mg}$ FFE-10 $\times$ ) resulted in lower peak plasma glucose concentrations at $30 \mathrm{~min}$ compared to the reference glucose drink $(P=0.003$ and $P=0.037$, respectively). No significant differences were detected between the peak 30 min glucose response for the reference glucose drink and either of the lower FFE doses (100 mg FFE-50× and 600 mg FFE-10x). Although a trend towards lower peak 30 min glucose concentrations was observed for the higher FFE doses compared to the corresponding smaller doses of the same extracts, these differences did not reach significance. 


\section{a}

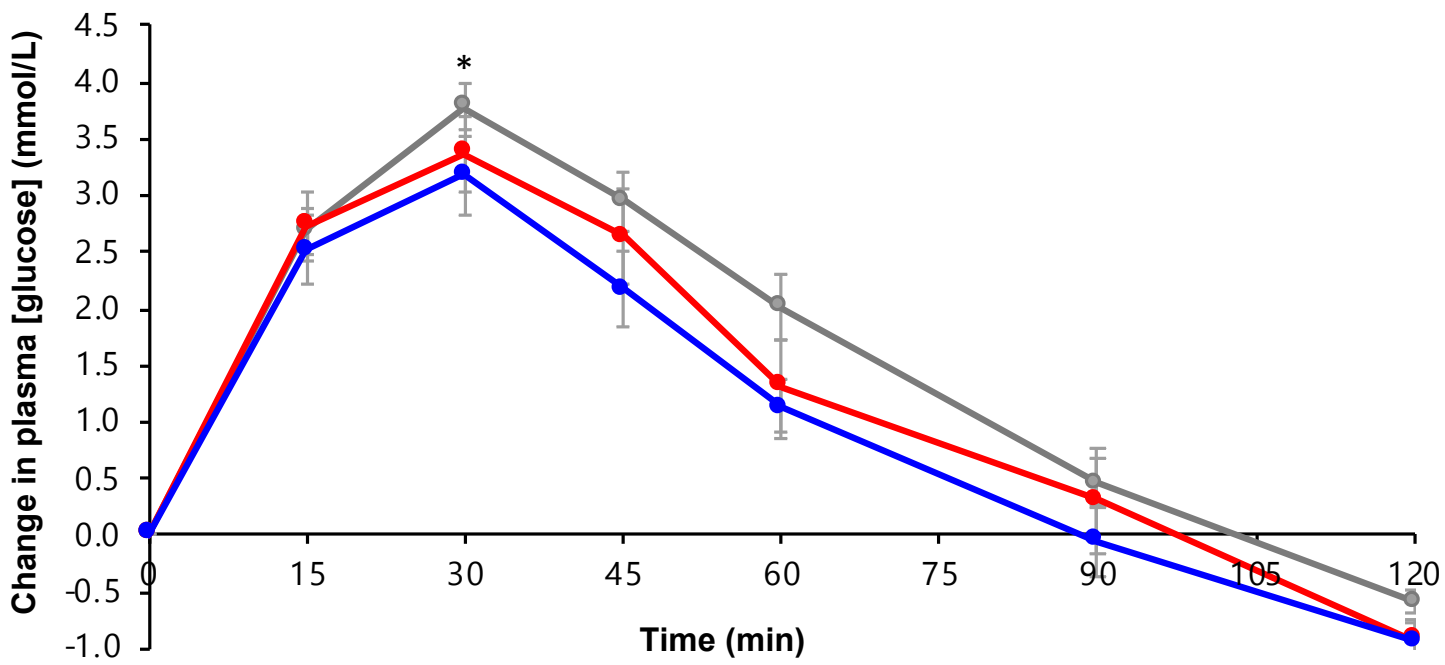

$\longrightarrow$ Reference glucose drink $\rightarrow$ ABALife $^{\mathrm{TM}}$ 50X $(100 \mathrm{mg}) \rightarrow$ ABALife $^{\mathrm{TM}}$ 50X (200 mg)

\section{b}

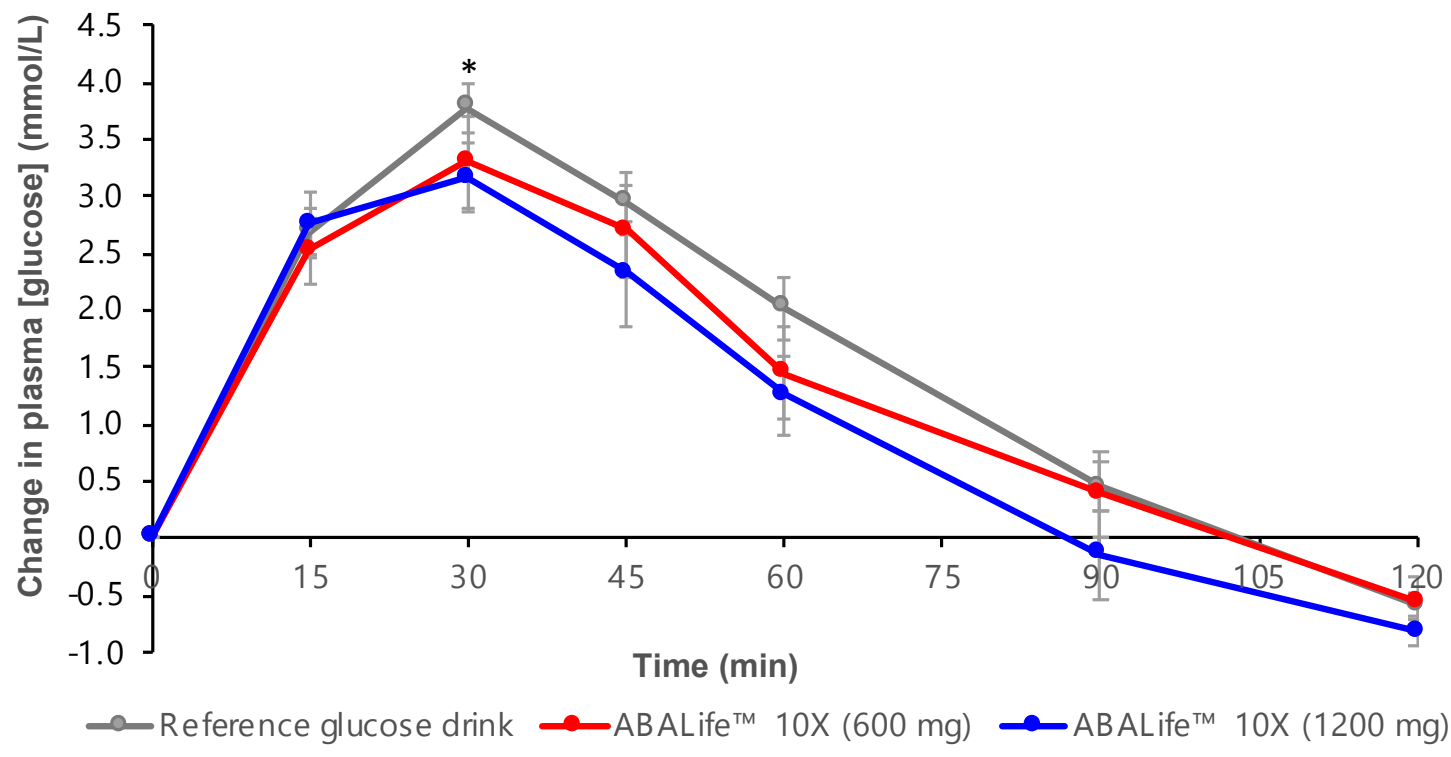

Figure 1. Change in postprandial $2 \mathrm{~h}$ plasma glucose concentration in healthy adults for (a) the two doses of abscisic acid (ABA) Life ${ }^{\mathrm{TM}} 50 \times$ fig fruit extract consumed with a glucose solution; (b) the two doses of ABA Life ${ }^{\mathrm{TM}} 10 \times$ fig fruit extract consumed with a glucose solution. Data are mean \pm standard error mean (SEM), $n=10$ for the 3 repeated tests in each participant for the reference glucose drink, and $n=10$ for each test drink containing fig fruit extract (FFE). The two lower doses of each fig fruit extract contained $40 \mu \mathrm{g}$ of abscisic acid (shown in red), and the two higher doses of each fig fruit extract contained $80 \mu \mathrm{g}$ of abscisic acid (shown in blue). * indicates a significant difference between peak 30 min glucose concentration for the high ABA dose test drinks (200 mg FFE-50× and $1200 \mathrm{mg}$ FFE-10× compared to the reference food $(P \leq 0.037)$.

Similar to plasma glucose response curves, the postprandial insulin response curves produced by the reference glucose solution and the four test beverages peaked at $30 \mathrm{~min}$ and gradually declined to preprandial levels by 120 min (Figure 2). All four FFE test beverages produced significantly lower peak plasma insulin concentrations at 30 min compared to the reference glucose drink $(P \leq 0.008)$. 
a
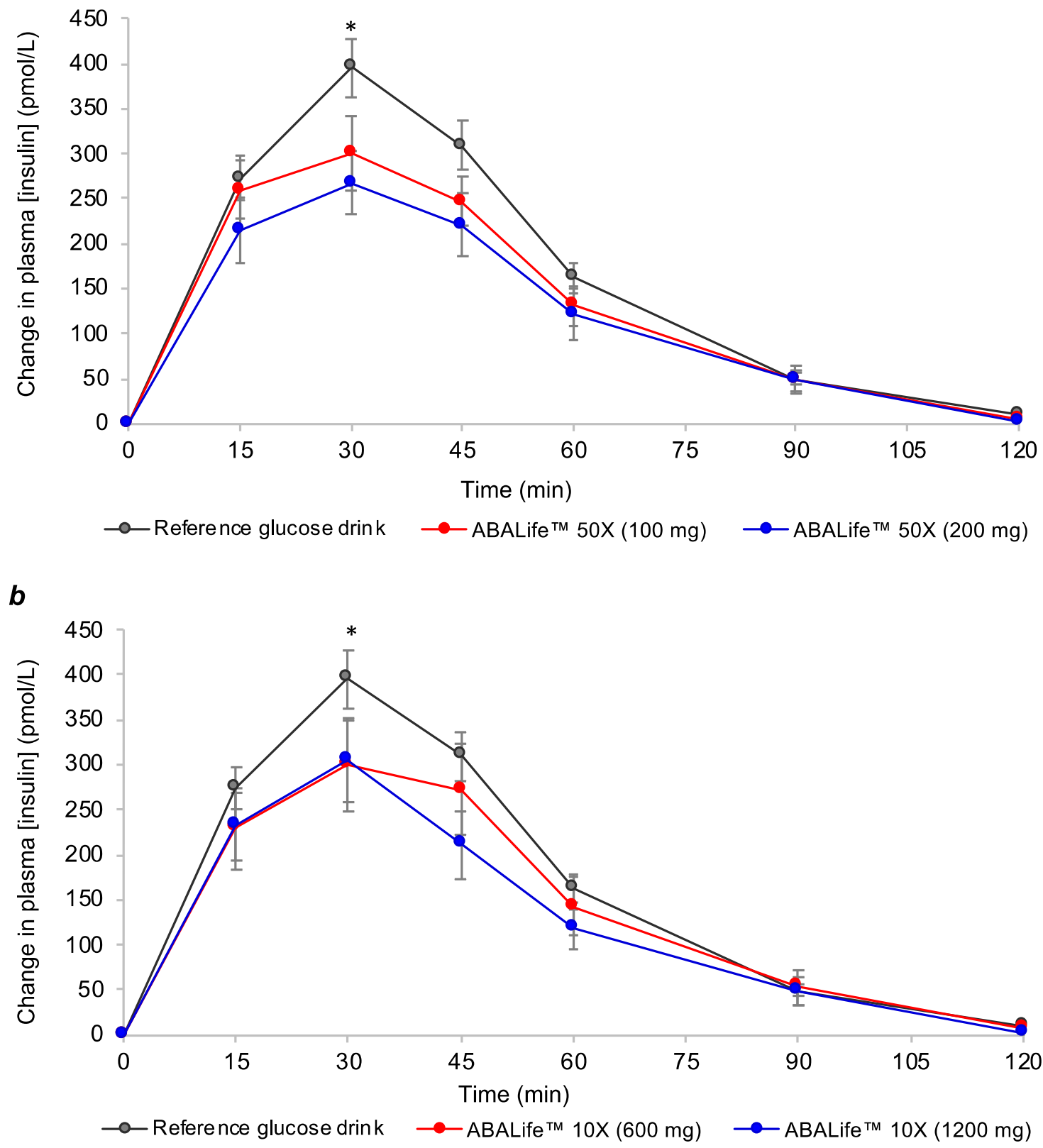

Figure 2. Change in postprandial $2 \mathrm{~h}$ plasma insulin concentration in healthy adults for (a) the two doses of ABA Life ${ }^{\mathrm{TM}} 50 \times$ fig fruit extract consumed with a glucose solution; (b) the two doses of ABA Life $^{\mathrm{TM}} 10 \times$ fig fruit extract consumed with a glucose solution. Data are mean \pm standard error mean (SEM), $n=10$ for the 3 repeated tests in each participant for the reference glucose drink, and $n=10$ for each test drink containing fig fruit extract (FFE). The two lower doses of each fig fruit extract contained $40 \mu \mathrm{g}$ of abscisic acid (shown in red), and the two higher doses of each fig fruit extract contained 80 $\mu \mathrm{g}$ of abscisic acid (shown in blue). * indicates a significant difference between peak $30 \mathrm{~min}$ insulin concentration for each test drink containing FFE compared to the reference food $(P \leq 0.019)$.

When data for the two test beverages containing $80 \mu \mathrm{g}$ ABA $(200 \mathrm{mg}$ FFE-50× and $1200 \mathrm{mg}$ FFE-10 $\times$ ) were combined together, the postprandial glycemic response was significantly lower than for the average $2 \mathrm{~h}$ glucose iAUC produced by the reference glucose drink $(152 \mathrm{mmol} / \mathrm{L} \cdot \mathrm{min}$ vs 203 $\mathrm{mmol} / \mathrm{L} \cdot \mathrm{min}, P=0.042$ ) (Figure 3 ). The two lower ABA dose test beverages (100 $\mathrm{mg}$ FFE-50 $\mathrm{x}$ and 600 mg FFE-10 $\times$ ) produced a nonsignificant reduction in glucose iAUC compared to the reference beverage. When the two test beverages containing $80 \mu \mathrm{g}$ of ABA were combined together ( $200 \mathrm{mg}$ FFE-50 $\mathrm{x}$ and 
$1200 \mathrm{mg}$ FFE-10×), the postprandial insulinemic response was significantly lower than the reference glucose drink (15157 pmol/L-min vs $19983 \mathrm{pmol} / \mathrm{L} \cdot \mathrm{min}, P=0.021)$ (Figure 3). The difference between the combined postprandial insulin iAUC for the two lower ABA dose beverages (100 mg FFE-50 $\times$ and $600 \mathrm{mg}$ FFE-10x) and the reference drink did not reach statistical significance.

a

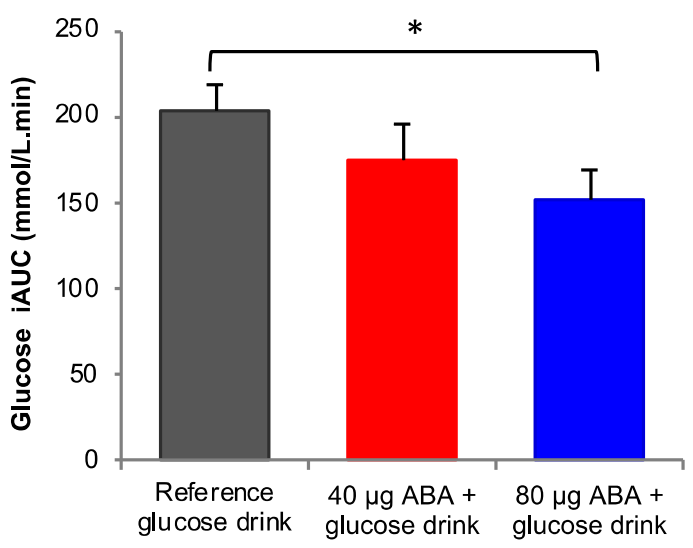

b

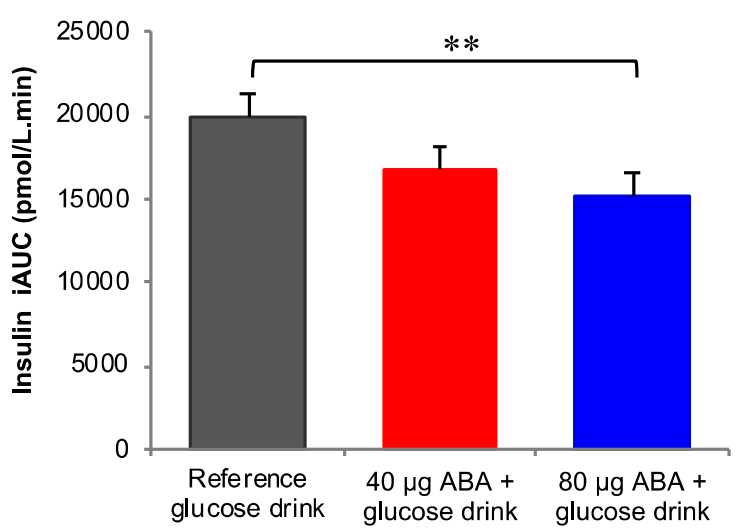

Figure 3. Two-hour incremental area under the curve (iAUC) responses for the two pooled lower $40 \mu \mathrm{g}$ abscisic acid (ABA) doses (100 mg FFE-50 $\times$ and $600 \mathrm{mg}$ FFE-10 $\times, n=20$, shown in red) and the two pooled higher doses of ABA ( $200 \mathrm{mg}$ FFE-50 $\times$ and $1200 \mathrm{mg}$ FFE- $10 \times n=20$, shown in blue) compared to the reference glucose drink $(n=30)$. (a) Postprandial glucose responses and $(\mathbf{b})$ postprandial insulin responses. Data are shown as mean \pm standard error mean (SEM). ${ }^{*}$ indicates a significant difference between pooled higher ABA dose compared to the reference glucose drink at $P=0.042 .{ }^{* *}$ indicates a significant difference between pooled higher ABA dose compared to the reference glucose drink at $P=$ 0.021 .

\subsection{Glycemic Index and Insulinemic Index of Test Beverages}

The addition of FFE to a glucose solution produced considerable reductions in both GI and II compared to the glucose solution consumed alone (Table 1). The two test beverages containing the higher dose of $80 \mu \mathrm{g}$ ABA (200 mg FFE-50× and $1200 \mathrm{mg}$ FFE-10× ) significantly lowered GI by $-25 \%$ $(P=0.001)$ and $-24 \%(P=0.002)$, respectively, and II by $-24 \%$ (both $P=0.001)$ compared to the reference glucose solution. Similarly, the two lower $40 \mu \mathrm{g}$ ABA test beverages also showed significant reductions in II by approximately $-15 \%$ (100 mg FFE-50 $\times, P=0.046$ and $600 \mathrm{mg}$ FFE-10 $\times, P=0.022)$ compared to the glucose solution alone, but the reductions in GI did not reach statistical significance. There was a significant dose-response effect, with increasing dose of ABA producing a greater reduction in GI and II of the glucose reference drink (trend $P<0.01$ for both GI and II).

Table 1. Glycemic index (GI) and insulinemic index (II) values for the four test beverages containing $\mathrm{ABALife}^{\mathrm{TM}}$ fig fruit extracts relative to the reference glucose solution $(\mathrm{GI}$ and $\mathrm{II}=100)$. Data are mean \pm SEM, $n=10$. The two lower doses of each fig fruit extract (FFE), $100 \mathrm{mg}$ FFE-50× and $600 \mathrm{mg}$ FFE-50×, contained $40 \mu \mathrm{g}$ abscisic acid, and the two higher doses of each FFE, $200 \mathrm{mg}$ FFE-50× and $1200 \mathrm{mg}$ FFE-10×, contained $80 \mu \mathrm{g}$ abscisic acid.

\begin{tabular}{|c|c|c|c|c|}
\hline Test Food & GI Value & $\begin{array}{c}\text { Mean GI } \\
\text { Difference }\end{array}$ & II Value & $\begin{array}{c}\text { Mean II } \\
\text { Difference } 1\end{array}$ \\
\hline Reference food (glucose drink) & 100 & - & 100 & - \\
\hline ABALife $^{\mathrm{TM}} 50 \times(100 \mathrm{mg})+$ glucose drink & $87 \pm 6$ & -13 & $86 \pm 5^{\#}$ & -14 \\
\hline ABALife $^{\mathrm{TM}} 50 \times(200 \mathrm{mg})+$ glucose drink & $75 \pm 6 *$ & -25 & $76 \pm 6^{*}$ & -24 \\
\hline ABALife $^{\mathrm{TM}} 10 \times(600 \mathrm{mg})+$ glucose drink & $86 \pm 5$ & -14 & $84 \pm 6^{* *}$ & -16 \\
\hline $\mathrm{ABALife}^{\mathrm{TM}} 10 \times(1200 \mathrm{mg})+$ glucose drink & $77 \pm 5 \ddagger$ & -24 & $76 \pm 5 *$ & -24 \\
\hline
\end{tabular}

${ }^{1}$ Mean difference relative to the reference glucose drink. ${ }^{*} P=0.001$ vs. reference drink; ${ }^{\ddagger} P=0.002$ vs. reference drink; ${ }^{* *} P=0.022$ vs. reference drink; ${ }^{\#} P=0.046$ vs. reference drink. 


\section{Discussion}

The present study shows that the addition of FFE to a standard beverage significantly reduced postprandial glycemic and insulinemic responses compared to the glucose beverage alone. The higher doses of ABA (200 mg FFE-50× and $1200 \mathrm{mg}$ FFE-10x) reduced glycemic and insulinemic responses by $\sim 25 \%$ in healthy adults. Our results indicate that FFE in relatively small quantities (100-1200 mg) may be a useful food fortification or supplementation strategy to help reduce the GI of high-GI foods or diets. A recent systematic review and meta-analyses reported a 10 unit reduction in GI was sufficient to produce significant risk reductions in the development of type 2 diabetes [23]. Acute consumption of FFE with a food produced a clear dose-response effect with clinically relevant reductions in GI and II.

Characterization of foods in terms of their GI and glycemic response has been a matter of continuous attention among the scientific community [24], as well as for individuals with insulin resistance. A number of different plant extracts have been shown to reduce postprandial glycemia or GI of common carbohydrates and carbohydrate-rich foods. Wang et al. reported that consumption of mulberry leaf extracts reduced the overall glycemic response, peak glucose concentrations at 30 min, and GI of glucose by $8.2 \%$ [25]. In our study, supplementation with FFE reduced GI to a greater extent $(13 \%-25 \%)$ compared to mulberry leaf extracts. Moreover, the reduction in glycemia achieved with FFE extracts at low dosages is superior to several available functional fiber preparations that are required at higher dosages $(\geq 5 \mathrm{~g} /$ day $\backslash)$ to achieve reduction in postprandial glycemia, which is only modest in many cases [26-28]. Soluble dietary fiber primarily acts by creating viscous gels that hinder glucose absorption, though some evidence exists for additional glucose-regulating effects in part through regulation of cholesterol and lipid levels in type 2 diabetes [29]. Soluble dietary fiber acts by creating viscous gels that hinder glucose absorption. However, addition of fiber can be associated with food palatability issues and often compromises the organoleptic appeal of foods. In addition, dietary fiber may increase the likelihood of gastrointestinal complaints, such as flatulence and diarrhea, due to its colonic fermentation properties [28]. In contrast, FFE has a different mechanism of action (ABA is a regulator of glucose disposal), does not create any viscosity issues or adverse gastrointestinal side effects, can be added to foods in relatively smaller quantities, and was well tolerated by all study participants.

Fruit and vegetable consumption patterns differ around the world, but we estimate ABA intake from these sources would range from approximately 160-260 $\mu \mathrm{g}$ ABA per day (on average fruits contain $0.62 \mu \mathrm{g} \mathrm{ABA} / \mathrm{g}$ and vegetables contain $0.29 \mu \mathrm{g} \mathrm{ABA} / \mathrm{g}$ [18]). The American Heart Association 2020 Strategic Goals recommend $\geq 4.5$ servings/day of fruits and vegetables [30], which is estimated to provide $\geq 297 \mu \mathrm{g}$ of ABA per day [18]. However, only $8 \%$ of the US adult population meets these dietary recommendations [31], suggesting that the majority of the population is consuming diets low in ABA, which could impact overall health outcomes. Dietary ABA has been shown to improve glucose tolerance in both experimental animals and healthy participants [9,19]. These published data in combination with our findings suggest that dietary ABA administration added into foods or beverages or potentially incorporated into the food matrix could be effective in improving glucose tolerance. The results of the present study show that FFEs containing ABA are an effective dietary intervention to produce significant reductions in GI and II of a high-GI glucose drink. Our data are comparable to results observed with synthetic ABA or a plant source of ABA [19]. Therefore, given the important role of low-GI diets in helping to improve glycemic control [32-34], consumption of FFE, such as $\mathrm{ABALife}^{\mathrm{TM}}$, could be a promising adjunctive dietary intervention for management of metabolic stress and chronic metabolic disorders.

The present study had certain limitations, including a small sample size of healthy participants with normal glucose tolerance and insulin sensitivity as well as a short duration, which only allowed the investigation of acute postprandial effects of the extracts. Randomized, placebo-controlled studies with larger numbers of participants and long-term trials are warranted to further confirm our observations. Specifically, studies including individuals with metabolic disorders, such as IGT, diabetes, or obesity, 
will help characterize the efficacy and engagement of LANCL2 by ABA in the target tissue. This further work may yield important new insights into preventive or therapeutic dietary strategies using ABA.

\section{Conclusions}

In summary, our study demonstrated that FFE standardized in ABA, when consumed in relatively small doses, can produce significant and clinically relevant reductions in postprandial glucose and insulin responses to a high-GI glucose drink. A similar dose-response reduction in GI and II values was observed for both the lower and higher extract concentrations, confirming that the FFE matrix did not influence the activity of ABA. Supplementation with FFE standardized in ABA, in the form of dietary supplements or functional beverages, may serve as a promising, novel nutritional intervention for the management of postprandial glucose homeostasis and metabolic disorders such as metabolic syndrome, prediabetes, and possibly diabetes and obesity.

\section{Patents}

A patent-pending process (EP17382616.5) was used to produce the dried fig fruit extracts (ABAlife $^{\mathrm{TM}}$, Euromed, Spain) investigated in this study.

Author Contributions: Conceptualization, F.S.A., A.V., and A.M.; funding acquisition, A.V., A.Z., and E.R.; methodology, investigation, visualization and formal analysis, F.S.A.; writing-original draft preparation F.S.A, A.Z.; writing - review and editing, all authors. All authors approved the final version of the manuscript.

Funding: This research was funded by Euromed S.A., Spain.

Acknowledgments: This study is part of a wider collaboration project with Josep Bassaganya-Riera, Biotherapeutics Inc., USA. The authors acknowledge CBCC Global Research LLP., Ahmedabad for providing assistance and support for development of manuscript.

Conflicts of Interest: A.V., A.M., A.Z., and E.R. are employed by Euromed S.A. The study funders (Euromed S.A.) had no role in the design, collection or analysis of the data. F.A. is the research manager of the Sydney University Glycemic Index Research Service that was contracted to conduct the study, but researchers were blinded to the treatments during the conduct of the study and during data analysis. F.A. is a co-author of popular books on the glycemic index and is a director of the Glycemic Index Foundation.

\section{References}

1. Edwards, C.M.; Cusi, K. Prediabetes: A worldwide epidemic. Endocrinol. Metab. Clin. N. Am. 2016, 45, 751-764. [CrossRef] [PubMed]

2. International Diabetes Federation. IDF Diabetes Atlas, 8th ed.; International Diabetes Federation: Brussels, Belgium, 2017; Available online: http://www.diabetesatlas.org (accessed on 29 October 2018).

3. Centers for Disease Control and Prevention. National Diabetes Statistics Report 2017; Centers for Disease Control and Prevention, U.S. Department of Health and Human Services: Atlanta, GA, USA, 2017. Available online: https://www.cdc.gov/diabetes/data/statistics/statistics-report.html (accessed on 29 October 2018).

4. Handelsman, Y.; Bloomgarden, Z.T.; Grunberger, G.; Umpierrez, G.; Zimmerman, R.S.; Bailey, T.S.; Blonde, L.; Bray, G.A.; Cohen, A.J.; Dagogo-Jack, S.; et al. American association of clinical endocrinologists and American college of endocrinology-Clinical practice guidelines for developing a diabetes mellitus comprehensive care plan-2015. Endocr. Pract. 2015, 21, 1-87. [CrossRef] [PubMed]

5. Bansal, N. Prediabetes diagnosis and treatment: A review. World J. Diabetes 2015, 6, 296-303. [CrossRef] [PubMed]

6. Karimi, A.; Majlesi, M.; Rafieian-Kopaei, M. Herbal versus synthetic drugs; beliefs and facts. J. Nephropharmacol. 2015, 4, 27-30. [PubMed]

7. Schulz, V. Safety of St. John's Wort extract compared to synthetic antidepressants. Phytomedicine 2006, 13, 199-204. [CrossRef] [PubMed]

8. Bruzzone, S.; Bodrato, N.; Usai, C.; Guida, L.; Moreschi, I.; Nano, R.; Antonioli, B.; Fruscione, F.; Magnone, M.; Scarfi, S.; et al. Abscisic Acid Is an Endogenous Stimulator of Insulin Release from Human Pancreatic Islets with Cyclic ADP Ribose as Second Messenger. J. Boil. Chem. 2008, 283, 32188-32197. [CrossRef] 
9. Guri, A.J.; Hontecillas, R.; Si, H.; Liu, D.; Bassaganya-Riera, J. Dietary abscisic acid ameliorates glucose tolerance and obesity-related inflammation in $\mathrm{db} / \mathrm{db}$ mice fed high-fat diets. Clin. Nutr. 2007, 26, 107-116. [CrossRef]

10. Qi, C.C.; Zhang, Z.; Fang, H.; Liu, J.; Zhou, N.; Ge, J.F.; Chen, F.H.; Xiang, C.B.; Zhou, J.N. Antidepressant effects of abscisic acid mediated by the downregulation of corticotrophin-releasing hormone gene expression in rats. Int. J. Neuropsychopharmacol. 2014, 18. [CrossRef]

11. Lu, P.; Bevan, D.R.; Lewis, S.N.; Hontecillas, R.; Bassaganya-Riera, J. Molecular modeling of lanthionine synthetase component C-like protein 2: A potential target for the discovery of novel type 2 diabetes prophylactics and therapeutics. J. Mol. Model. 2011, 17, 543-553. [CrossRef]

12. Sturla, L.; Fresia, C.; Guida, L.; Bruzzone, S.; Scarfi, S.; Usai, C.; Fruscione, F.; Magnone, M.; Millo, E.; Basile, G.; et al. LANCL2 Is Necessary for Abscisic Acid Binding and Signaling in Human Granulocytes and in Rat Insulinoma Cells. J. Boil. Chem. 2009, 284, 28045-28057. [CrossRef]

13. Zeng, M.; Van Der Donk, W.A.; Chen, J. Lanthionine synthetase C-like protein 2 (LanCL2) is a novel regulator of Akt. Mol. Boil. Cell 2014, 25, 3954-3961. [CrossRef] [PubMed]

14. Sato, M.; Dehvari, N.; Dallner, O.S.; Olsen, J.M.; Csikasz, R.I.; Summers, R.J.; Hutchinson, D.S.; Bengtsson, T.; Öberg, A.I.; Sandström, A.L. Improving Type 2 Diabetes Through a Distinct Adrenergic Signaling Pathway Involving mTORC2 That Mediates Glucose Uptake in Skeletal Muscle. Diabetes 2014, 63, 4115-4129. [CrossRef] [PubMed]

15. Bruzzone, S.; Ameri, P.; Briatore, L.; Mannino, E.; Basile, G.; Andraghetti, G.; Grozio, A.; Magnone, M.; Guida, L.; Scarfi, S.; et al. The plant hormone abscisic acid increases in human plasma after hyperglycemia and stimulates glucose consumption by adipocytes and myoblasts. FASEB J. 2012, 26, 1251-1260. [CrossRef] [PubMed]

16. Ameri, P.; Bruzzone, S.; Mannino, E.; Sociali, G.; Andraghetti, G.; Salis, A.; Ponta, M.L.; Briatore, L.; Adami, G.F.; Ferraiolo, A.; et al. Impaired Increase of Plasma Abscisic Acid in Response to Oral Glucose Load in Type 2 Diabetes and in Gestational Diabetes. PLoS ONE 2015, 10, e0115992. [CrossRef] [PubMed]

17. Vilsbøll, T.; Krarup, T.; Sonne, J.; Madsbad, S.; Vølund, A.; Juul, A.G.; Holst, J.J. Incretin Secretion in Relation to Meal Size and Body Weight in Healthy Subjects and People with Type 1 and Type 2 Diabetes Mellitus. J. Clin. Endocrinol. Metab. 2003, 88, 2706-2713. [CrossRef] [PubMed]

18. Zocchi, E.; Hontecillas, R.; Leber, A.; Einerhand, A.; Carbo, A.; Bruzzone, S.; Tubau-Juni, N.; Philipson, N.; Zoccoli-Rodriguez, V.; Sturla, L.; et al. Abscisic Acid: A Novel Nutraceutical for Glycemic Control. Front. Nutr. 2017, 4, 24. [CrossRef] [PubMed]

19. Magnone, M.; Ameri, P.; Salis, A.; Andraghetti, G.; Emionite, L.; Murialdo, G.; De Flora, A.; Zocchi, E. Microgram amounts of abscisic acid in fruit extracts improve glucose tolerance and reduce insulinemia in rats and in humans. FASEB J. 2015, 29, 4783-4793. [CrossRef] [PubMed]

20. Jenkins, D.J.; Wolever, T.M.; Taylor, R.H.; Barker, H.; Fielden, H.; Baldwin, J.M.; Bowling, A.C.; Newman, H.C.; Jenkins, A.L.; Goff, D.V. Glycemic index of foods: A physiological basis for carbohydrate exchange. Am. J. Clin. Nutr. 1981, 34, 362-366. [CrossRef] [PubMed]

21. Wolever, T.M.S.; Brand-Miller, J.C.; Abernethy, J.; Astrup, A.; Atkinson, F.; Axelsen, M.; Björck, I.; Brighenti, F.; Brown, R.; Brynes, A.; et al. Measuring the glycemic index of foods: Interlaboratory study. Am. J. Clin. Nutr. 2008, 87, 247S-257S. [CrossRef] [PubMed]

22. International Organization for Standardization. ISO 26642:2010: Food Products-Determination of the Glycaemic Index (GI) and Recommendation for Food Classification; ISO: Geneva, Switzerland, 2010.

23. Liu, S.; Salas-Salvadó, J.; La Vecchia, C.; Poli, A.; Ha, M.-A.; Baer-Sinnott, S.; Brand-Miller, J.C.; Livesey, G.; Taylor, R.; Livesey, H.F.; et al. Dietary Glycemic Index and Load and the Risk of Type 2 Diabetes: A Systematic Review and Updated Meta-Analyses of Prospective Cohort Studies. Nutrients 2019, 11, 1280.

24. Augustin, L.; Kendall, C.W.; Jenkins, D.J.; Willett, W.C.; Astrup, A.; Barclay, A.W.; Björck, I.; Brand-Miller, J.C.; Brighenti, F.; Buyken, A.E.; et al. Glycemic index, glycemic load and glycemic response: An International Scientific Consensus Summit from the International Carbohydrate Quality Consortium (ICQC). Nutr. Metab. Cardiovasc. Dis. 2015, 25, 795-815. [CrossRef] [PubMed]

25. Wang, R.; Li, Y.; Mu, W.; Li, Z.; Sun, J.; Wang, B.; Zhong, Z.; Luo, X.; Xie, C.; Huang, Y. Mulberry leaf extract reduces the glycemic indexes of four common dietary carbohydrates. Medicine 2018, 97, e11996. [CrossRef] [PubMed] 
26. Gibb, R.D.; McRorie, J.W.; Russell, D.A.; Hasselblad, V.; D’Alessio, D. Psyllium fiber improves glycemic control proportional to loss of glycemic control: A meta-analysis of data in euglycemic subjects, patients at risk of type 2 diabetes mellitus, and patients being treated for type 2 diabetes mellitus. Am. J. Clin. Nutr. 2015, 102, 1604-1614. [CrossRef] [PubMed]

27. Pastors, J.G.; Blaisdell, P.W.; Balm, T.K.; Asplin, C.M.; Pohl, S.L. Psyllium fiber reduces rise in postprandial glucose and insulin concentrations in patients with non-insulin-dependent diabetes. Am. J. Clin. Nutr. 1991, 53, 1431-1435. [CrossRef] [PubMed]

28. Groop, P.H.; Aro, A.; Stenman, S.; Groop, L. Long-term effects of guar gum in subjects with non-insulin-dependent diabetes mellitus. Am. J. Clin. Nutr. 1993, 58, 513-518. [CrossRef]

29. Breneman, C.B.; Tucker, L. Dietary fibre consumption and insulin resistance-The role of body fat and physical activity. Br. J. Nutr. 2013, 110, 375-383. [CrossRef] [PubMed]

30. Lloyd-Jones, D.M.; Hong, Y.; Labarthe, D.; Mozaffarian, D.; Appel, L.J.; Van Horn, L.; Greenlund, K.; Daniels, S.; Nichol, G.; Tomaselli, G.F.; et al. Defining and Setting National Goals for Cardiovascular Health Promotion and Disease Reduction. Circulation 2010, 121, 586-613. [CrossRef] [PubMed]

31. Rehm, C.D.; Penalvo, J.L.; Afshin, A.; Mozaffarian, D. Dietary intake among US adults. 1999-2012. JAMA 2016, 315, 2542-2553. [CrossRef]

32. Brand-Miller, J.; Hayne, S.; Petocz, P.; Colagiuri, S. Low-Glycemic Index Diets in the Management of Diabetes: A meta-analysis of randomized controlled trials. Diabetes Care 2003, 26, 2261-2267. [CrossRef]

33. Elliott, E.J.; Thomas, D. Low glycaemic index, or low glycaemic load, diets for diabetes mellitus. Cochrane Database Syst. Rev. 2009. [CrossRef]

34. Eleazu, C.O. The concept of low glycemic index and glycemic load foods as panacea for type 2 diabetes mellitus; prospects, challenges and solutions. Afr. Heal. Sci. 2016, 16, 468-479. [CrossRef] [PubMed]

(C) 2019 by the authors. Licensee MDPI, Basel, Switzerland. This article is an open access article distributed under the terms and conditions of the Creative Commons Attribution (CC BY) license (http://creativecommons.org/licenses/by/4.0/). 